\title{
Sports TV Rights Sales Analysis
}

\author{
Kang TAN \\ Chengdu Sports University, Chengdu, China
}

\begin{abstract}
In recent years, the sports TV rights sales prices rose rapidly, increasingly diversified sales, sales of television rights has become the main source of major sports events, the paper will be sold in an initial basic understanding of sports TV rights situation Based on the sales of sports TV rights to explore ways to provide reference for the development of sports TV rights market.
\end{abstract}

KEYWORD: Sports TV rights; sales; analysis

\section{INTRODUCTION}

After the formation of sports TV rights market, to make the purchase and sale agreement between the parties to complete the transaction, the most important thing is to be reasonable and appropriate marketing tool, the way sports TV rights contributed to the successful completion of the transaction, and to ensure the smooth implementation of the relevant agreements. With the growing prosperity of sports TV rights market, the various sports organizations, sports event organizers, television media in order to protect their own interests as a starting point, and made use of a wide variety of sports TV rights sales.

\section{RESULTS}

\subsection{Open tender}

With the rapid popularization of sports worldwide boom and the rise of television, sports TV rights to become self-image to show, to prove the strength and a good opportunity to make a profit. Faced with a country or region to compete in a number of television, the IOC, FIFA, IAAF and other sports organizations or the Organizing Committee of Olympic Organizing Committee and other tender often adopt a fair, just and open manner [1]. It is composed of a number of broadcasters under fair conditions for bidding way to get the world-famous event TV rights, and in this way to improve the Olympics, World Cup television rights price and other events have played a positive role. Such as the 1984 Los Angeles Olympics, Ueberroth in this manner will be the exclusive broadcast rights buyout, so the price of broadcast rights straight up, and finally $\mathrm{ABC}(\mathrm{ABC})$ invested \$ 225 million acquired exclusive broadcast rights for the Olympic Games in the United States almost equivalent to the Montreal Olympics broadcast fees 10 times. After the 2001 International Olympic Committee President Jacques Rogge took office the new, strict rules of bidding and bid process televised Olympic Games, and the 2010 and 2012 Olympic Games were two public tender[2]. This means that the IOC sales of TV rights will be more fair and norms.

Although, when you open bidding internationally renowned sports organizations during these events TV rights bidding, want the higher the price the better, but they still want to participate in the final bidding of the overall strength of the television media to make consideration and evaluation, not blindly blind pursuit of broadcasting rights transfer artificially high prices, and increase the risk of their last televised sporting events of its failure. So, you also need to consider many factors surface broadcast coverage, broadcast systems, and high-tech applications.

\subsection{Centralized sales}

Under the influence of global economic integration, the sports TV rights sales also showed a tendency to focus sales. In essence, focus on sales of broadcast rights is to prevent or reduce competition in the sale of broadcast rights issues within the Union between the clubs. Concentrate sales are sold separately in relation to the purposes of the club. The advantage is that the event can become more exciting, to improve the social influence of the tournament, while allowing event organizers have sufficient strength 
and ability to deal with broadcasters, sports TV rights are also available to the ideal selling price. In addition, this approach can reduce the gap between rich and professional clubs[3]. A lot of TV rights events in Europe and the United States have adopted the sales. Such as the four major US professional leagues have implemented a centralized sale of TV rights of way. NBA, MLB and the cost of the national broadcast rights to NHL three races negotiate alliances with broadcast networks by local negotiations by each team and the local TV station. NFL events only sold nationwide broadcast rights and prohibit local broadcast network broadcast the game on the local market[4] . In the Spanish football league by Celta, Mallorca and other eight La Liga club and all 22 B team consisting of "G30" is also true that because of the weaker teams, so the lack of respect in television attractive. This 30 team had to put their TV rights sold to professional league, and then by the professional league in the name of a collective contract with the television company, the last professional football league and then in between the club dividends.

Although sales in the sports broadcast rights of each professional sports league will be limited more or less anti-monopoly law and other regulations, but professional leagues still many obstacles to overcome to get the concentration of power in the sale of TV rights. Centralized selling television rights has greatly enhanced the bargaining power of the league, making professional league in the negotiation of television rights can play a leading role in promoting the development of professional sports television rights to flourish. It also enhances the viability of the professional clubs.

\subsection{Buyers and sellers face to face consultations}

Broadcast rights for both parties face to face consultations to finalize the transfer price of sports TV rights is an original TV rights transfer mode. So far, this transaction is still one way broadcast rights transfer the most common way. A country or region often have a television institution is the most powerful and the most authoritative, non-missionbroadcast major international competitions it perfectly. Like the United States, NBC, Japan's NHK, Canada's CTV, Europe, VER, China Central Television. [Weng Biao: "sports on TV Right for research," Sport Science 1999 Vol. 19, No. 3.] When the Olympics, World Cup, NBA, five leagues and other events organized by the world-famous, these TV operators directly negotiate the sale of broadcast rights matters and the Organizing Committee or sports organization, the price face consultations. Such as the 1995 fight of the broadcast rights for the Olympic Games, a total of five media organizations involved, after long and arduous negotiations in person, after negotiations, the International Olympic
Committee on the basis of a comprehensive study on the final straight signed a five Olympic Games and NBC value 35 billion in broadcast rights contract. [GiGi: "NBC gamble rings", Chinese sports in 2003 on seven.] Currently, the World Series of broadcast rights to use more transactions in person consultation with a combination of public bidding, which not only steadily increased the price of the TV rights for the Olympics and other competitions, but also easy to maintain long-term partnerships with television providers, after all, a relatively sound balance compromise scientific, fair and interests of all parties.

Broadcast rights for both parties face to face consultations to finalize the transfer price of sports TV rights is an original TV rights transfer mode. So far, this transaction is still one way broadcast rights transfer the most common way. A country or region often have a television institution is the most powerful and the most authoritative, non-missionbroadcast major international competitions it perfectly. Like the United States, NBC, Japan's NHK, Canada's CTV, Europe, VER, China Central Television. When the Olympics, World Cup, NBA, five leagues and other events organized by the worldfamous, these TV operators directly negotiate the sale of broadcast rights matters and the Organizing Committee or sports organization, the price face consultations. Such as the 1995 fight of the broadcast rights for the Olympic Games, a total of five media organizations involved, after long and arduous negotiations in person, after negotiations, the International Olympic Committee on the basis of a comprehensive study on the final straight signed a five Olympic Games and NBC value 35 billion in broadcast rights contract[5] . Currently, the World Series of broadcast rights to use more transactions in person consultation with a combination of public bidding, which not only steadily increased the price of the TV rights for the Olympics and other competitions, but also easy to maintain long-term partnerships with television providers, after all, a relatively sound balance compromise scientific, fair and interests of all parties.

\subsection{Advertising replacement}

Advertising is a way of replacement sports TV rights deal in common. Games Organizing Committee and sports organizations will transfer to the television broadcasting rights organizations, broadcasters do not directly pay to the seller, but paid in equivalent advertising time. Advertising content can be related to the tournament videos can also be commercial advertising. This sports broadcast rights trading is often a transitional way sports TV rights market is not yet mature, but it is more common. And this sport is often the few people interested in the lowlevel sporting events, TV operators are often 
reluctant to directly pay for their TV rights. As compensation for the transfer of the Football League and the National Games TV rights, the organizing committee will deal with CCTV is often used in this way. In addition, there is a disguised form of advertising replacement method is to buy the right of sports broadcast rights to broadcast a file or sports programs, parties to the transaction agreed in advance in the contract: the seller's ad program must be fixed location in a program broadcast by the buyer When the entire broadcast, not free to cut or change their advertising to the buyer, if violated, the buyer will assume the associated financial compensation and legal liability. Such as CCTV and local stations broadcast NBA purchased ESPN programs have this situation exists.

\subsection{Intermediary operation}

TV rights sales sports competition is a commercial operation, the purpose is to seek to maximize the economic benefits, but this is a complicated project. To event organizers, the goal of achieving the desired business operations is extremely difficult. Therefore, many international sports organizations and national sports associations TV rights sales agency commissioned to make the phase separation of ownership and management. Thus greatly facilitate the management and sale of TV rights. In the early 1970 s of the 20th century, began to explore the commercial value of the FIFA football, agency commission on sales of television rights, the implementation of sales agents. So that FIFA and its major event - the World Cup into the rapid development period. The advantage of this model is that the operation by professional intermediaries, can improve the efficiency and economic benefits. But perhaps cautious when selecting intermediaries must be large by international agencies selling broadcast rights to the agent, and these agencies should do what, otherwise you will put yourself at risk. Such as 2002, 2006 and 2010 World Cup broadcast rights rests agency for distribution after the buyout. But after holding the last two World Cup broadcast rights for both agency ISL Switzerland and Germany Rocky Hill Group are due to spend huge sums of money to win the World Cup television rights has overwhelmed bankruptcy.

\subsection{Bundling}

Major sporting events in the development of TV rights, and the IOC has experienced. Taking into account the development of Olympic television advertisers will take a long period, if the rightsholding broadcasters no existing customers, invested heavily in the purchase of TV rights would not withdraw protection. In order to maintain the right of broadcasters have plenty of time to find advertisers and establish long-term stable cooperative relations, while also eliminating the trouble of TV rights negotiations again four years. Since 1995, the International Olympic Committee will be changed to the next session of the retail bundling several sessions of Olympic television rights to begin implementing long-term TV rights sales strategy. As in 1995, the US NBC television company signed with the IOC television agreement, the price of $\$ 2.5$ billion in 2004 and acquired in 2008 Summer Olympics, the 2006 Winter Olympic TV rights. Since June of that year, the IOC has signed to 2008 \$ 5.1 billion television contract with the United States, Australia, Japan, Central and South America, the Middle East, Europe and Asia. IOC this new sales approach can effectively reduce or avoid the impact of the Olympic Games and other world economic turmoil and has attracted famous international sports organizations such as FIFA's strong concern and follow.

\subsection{Joint purchase}

Due to the increasing cost of televised sports events increased, a single broadcast companies often bear the huge costs, resulting in a number of media events come together to buy broadcast rights trend. As January 2002, NBA with TNT, ABC, ESPN signed a six-year company worth $\$ 4.6$ billion television contract. [Wang Xiaodong: "The US professional sports television rights to develop research," Sports Culture Guide 2007 Section 2.] 2008 by Shandong, Liaoning, Jiangsu, Hubei, Xinjiang province sports channel consisting of five Chinese TV sports network platform (CSPN) also jointly purchased the broadcast rights for the European Championship tournament, made a good dissemination of results. Joint purchase of TV rights mechanisms, for the television company, dispersed bring huge investment in high-risk, while also expanding the breadth and depth of the event spread, and ultimately benefit the development of the television market, making participation in the joint purchase of broadcasting the right to get the healthy development of the television media.

\section{CONCLUSIONS}

Due to our late start in sports television, television sports rights market in the country is not mature. Our sports department in charge with the relevant departments should develop appropriate regulations televised sports, a reasonable distribution system, mobilize the enthusiasm to regulate sports television market. In sports broadcasting process, it is necessary to consider the economic benefits, but also consider the social benefits, among different regions 
to strengthen the television media agencies, to share resources, benefit sharing, risk sharing. This helps to improve the broadcast efficiency, but also help save capital. Currently, the sports television rights paid transfer of more single way, no longer meet the needs of the times, based on the use of China's existing television rights transfer mode on the United States and Europe should actively learn from the experience of mature, better development Sports Intangible market in order to promote the further development of sports.

\section{REFERENCES}

[1] Weng Biao, sports on TV Right for research, Sport Science, Vol. 19, Mar.1999, pp.28-29.

[2] Zhang Yahui, Modern Olympic TV rights management and marketing, Sports Science Institute of Shanxi Normal University, Vol. 10, Dec.2007, pp.46.

[3] Jiang Xinmiao, sports competitions transnational television rights via Transfer Dispute, Beijing Sport University, Vol. 11, Nov.2004, pp.62.

[4] Wang Xiaodong, The US professional sports television rights to develop research, Sports Culture Guide, Vol. 2, Feb.2007, pp.33.

[5] Gi Gi, NBC gamble rings, Chinese sports, Vol. 7, Jul.2003, pp.71. 